\title{
STRUCTURAL RELATIONSHIPS BETWEEN SENFOLOMYCINS AND PAULOMYCINS
}

\author{
A. D. Argoudelis, ${ }^{\dagger}$ L. Baczynskyj, S. A. Mizsak, \\ F. B. SHILLIDAY and P. F. WILEY ${ }^{\dagger}$ \\ The Upjohn Company, \\ Kalamazoo, MI 49001, U.S.A.
}

(Received for publication March 24, 1988)

\begin{abstract}
Senfolomycins A and B (Antimicrob. Agents Chemother. -1965: 828 831, 1966) are two antibacterial agents with physico-chemical and biological properties similar to those of paulomycin. Recent studies indicate that senfolomycin $\mathrm{A}\left(\mathrm{C}_{29} \mathrm{H}_{36} \mathrm{~N}_{2} \mathrm{O}_{18} \mathrm{~S}\right.$, MW 700) has molecular composition and fast atom bombardment MS fragmentation pattern identical to those of paulomycin E. Extensive NMR work indicates that the two antibiotics, which have been separated by HPLC and TLC, differ only in the stereochemistry of the $\mathrm{OCH}_{3}$ group present in their respective sugar moieties. Indirect evident suggests that senfolomycin $\mathrm{B}$ is dihydrosenfolomycin $A\left(\mathrm{C}_{88} \mathrm{H}_{38} \mathrm{~N}_{2} \mathrm{O}_{18} \mathrm{~S}\right.$, MW 702) and in this respect it is related to paulomycin $\mathrm{F}$. The proposed structures for senfolomycins $\mathrm{A}$ and $\mathrm{B}$ are discussed.
\end{abstract}

Previous publications discussed paulomycins $\mathrm{A}$ and $\mathrm{B}^{12}$ which are the main components of the antibiotic mixture produced by Streptomyces paulus. The minor components, paulomycins $\mathrm{A}_{2}, \mathrm{C}, \mathrm{D}$, $E$, and $F$ were discussed recently. ${ }^{2}$ The present paper details the studies which helped to elucidate the structural relationship of paulomycins and senfolomycins A and B, two antibiotics reported in 1965 by MITSCHER and his co-workers. ${ }^{3)}$

\section{Experimental}

Assay and Testing Procedures

The purification of antibiotics was measured by a microbiological disc-plate assay procedure with Micrococcus luteus as the assay organism.

\section{TLC Procedures}

The antibiotics were separated by TLC using BRINKMAN's cellulose-coated plates and $\mathrm{pH} 7.0$, $0.1 \mathrm{M}$ phosphate buffer as the mobile phase. Bioactive materials were observed by bioautography on $M$. luteus-seeded agar trays.

\section{Analytical HPLC}

All HPLC chromatography was carried out with a Varian Model 5560 (Varian Instruments, Sugar Land, Texas) instrument equipped with a LKB Rapid Spectral Detector (LKB, Broma, Sweden). A Zorbax C-8 $25 \mathrm{~cm} \times 4.6 \mathrm{~mm}$ stainless steel column packed with C-8 $(6 \mu \mathrm{m})$ reverse phase silica was used. The chromatogram was run isocratically using water - THF - acetonitrile $(3: 1: 1)$ containing $0.25 \mathrm{M}$ acetic acid, as the mobile phase. A $10-\mu 1$ sample was usually injected.

\section{Spectroscopic Methods}

UV spectra were obtained in methanol using a Perkin-Elmer Lambda 7 spectrophotometer, IR spectra were run in Nujol mull using a Digilab FTS-ISE spectrometer. ${ }^{1} \mathrm{H}$ NMR spectra were recorded on a Varian XL-200 spectrometer operating at $200 \mathrm{MHz}$. Solutions (ca. $0.4 \mathrm{ml}, \mathrm{ca} .0 .25 \mathrm{M}$ )

t Dr. A. D. ARgoudelis and Dr. P. F. WILEY, leaders in the studies of the paulomycin family of antibiotics died on July 19, 1988, and Sept. 15, 1987, respectively. This paper is dedicated to their memory. 
of the compounds in deuterated chloroform or acetone were used. ${ }^{13} \mathrm{C}$ NMR spectra were recorded on a Varian CFT-20 spectrometer operating at $20.0 \mathrm{MHz} .{ }^{1} \mathrm{H}$ and ${ }^{13} \mathrm{C}$ NMR chemical shifts are reported as ppm relative to TMS. Negative ion MS were obtained on a V. G. Analytical ZAB-2F high-resolution (HR) mass spectrometer using a fast atom bombardment (FAB) source. Bombarding gas, xenon, accelerating voltage $7.0 \mathrm{KeV}$; matrix, tetraethylene glycol (Aldrich Chemical Co., Milwaukee, WI, U.S.A.).

Materials

Paulomycins E and F were obtained as described by Argoudelis et al. ${ }^{2)}$ Senfolomycin A was provided by Lederle Laboratories, a division of Cyanamid Co., U.S.A.

\section{Results and Discussion}

In 1976, WILEY reported the isolation of paulomycin ${ }^{4}$ from fermentations of $S$. paulus strain AT111 (UC 5231, NRRL 8115) which was later found to be a mixture of paulomycins A and B in almost equal amounts. WILEY noted and discussed the similarities between paulomycin and senfolomycins A and B, two antibiotics reported in 1965 by Mrrscher and his co-workers at Lederle Laboratories. ${ }^{3,5)}$ The properties of paulomycin and senfolomycins $\mathrm{A}$ and B as reported by WrLEY and MITSCHER are shown in Table 1. The analytical values could not differentiate these compounds. The molecular weights and formulas reported were estimated from $\mathrm{N}$ or $\mathrm{S}$ determination and could not be used for identification purposes. The UV and IR spectra were very similar and, like in the case of the paulomycin complex, cannot be used for differentiation of these antibiotics.

Paulomycin and senfolomycins A and B have negative rotations in methanol. However, paulomycin exhibits positive rotation when chloroform was used as the solvent while senfolomycin $A$ has increased negative rotation in chloroform. No rotation value was reported for senfolomycin B in chloroform. This presented the first evidence that paulomycin is different from senfolomycin A. WILEY also compared paulomycin to an authentic sample of senfolomycin A by TLC and he was able to separate these compounds on silica gel using methyl ethyl ketone - acetone - water $(70: 20: 11)$ as the mobile phase. Paulomycin moved in this system faster than senfolomycin A. Senfolomycin B was not available for comparison. However, the differences in optical rotation in methanol, $-34.9^{\circ}$ for paulomycin vs. $-60^{\circ}$ for senfolomycin B indicated that they were not same. Furthermore, senfolomycin B is more polar than senfolomycin A and is expected to move much slower than senfolomycin

Table 1. Physical and chemical properties of paulomycin and senfolomycins A and B.

\begin{tabular}{|c|c|c|c|}
\hline & Paulomycin & Senfolomycin A & Senfolomycin B \\
\hline Anal C: & 51.00 & 49.66 & 49.15 \\
\hline $\mathrm{H}:$ & 5.53 & 5.28 & 5.71 \\
\hline $\mathrm{N}:$ & 3.50 & 3.81 & 3.93 \\
\hline S: & 4.01 & 4.57 & 4.44 \\
\hline MW (estimates) & 800 & $800 \sim 828$ & $714 \sim 720$ \\
\hline $\begin{array}{l}\text { Molecular formulas } \\
\text { (estimates) }\end{array}$ & $\mathrm{C}_{34} \mathrm{H}_{44} \mathrm{~N}_{2} \mathrm{SO}_{18}$ & $\mathrm{C}_{33 \sim 35} \mathrm{H}_{40 \sim 44} \mathrm{~N}_{2} \mathrm{SO}_{19}$ & - \\
\hline UV $\lambda_{\max }(\mathrm{a})$ & $\begin{array}{l}239(17.3), 275(12.2) \\
321(12.2)\end{array}$ & $\begin{array}{l}236(23.0), 277(15.4) \\
322(13.6)\end{array}$ & $\begin{array}{l}236(22.0), 277(15.5) \\
322(14.0)\end{array}$ \\
\hline IR & $\begin{array}{l}3560,2050,1730,1700 \\
1690(\mathrm{sh}), 1620\end{array}$ & $\begin{array}{l}3335,2040,1739,1695 \\
1639,1626\end{array}$ & $\begin{array}{l}3389,2044,1739,1695 \\
1626,1590\end{array}$ \\
\hline$[\alpha]_{D}^{25^{\circ}}$ & $-34.9^{\circ}$ (c $\left.1.0, \mathrm{MeOH}\right)$ & $-58.0^{\circ}(c 0.9, \mathrm{MeOH})$ & $-60.0^{\circ}(c 0.9, \mathrm{MeOH})$ \\
\hline
\end{tabular}


Fig. 1. FAB-MS spectra of paulomycin $\mathrm{E}\left(\mathrm{C}_{29} \mathrm{H}_{36} \mathrm{~N}_{2} \mathrm{O}_{16} \mathrm{~S}\right)(\mathrm{A})$ and senfolomycin $\mathrm{A}\left(\mathrm{C}_{28} \mathrm{H}_{36} \mathrm{~N}_{2} \mathrm{O}_{18} \mathrm{~S}\right)$ (B).

(A)

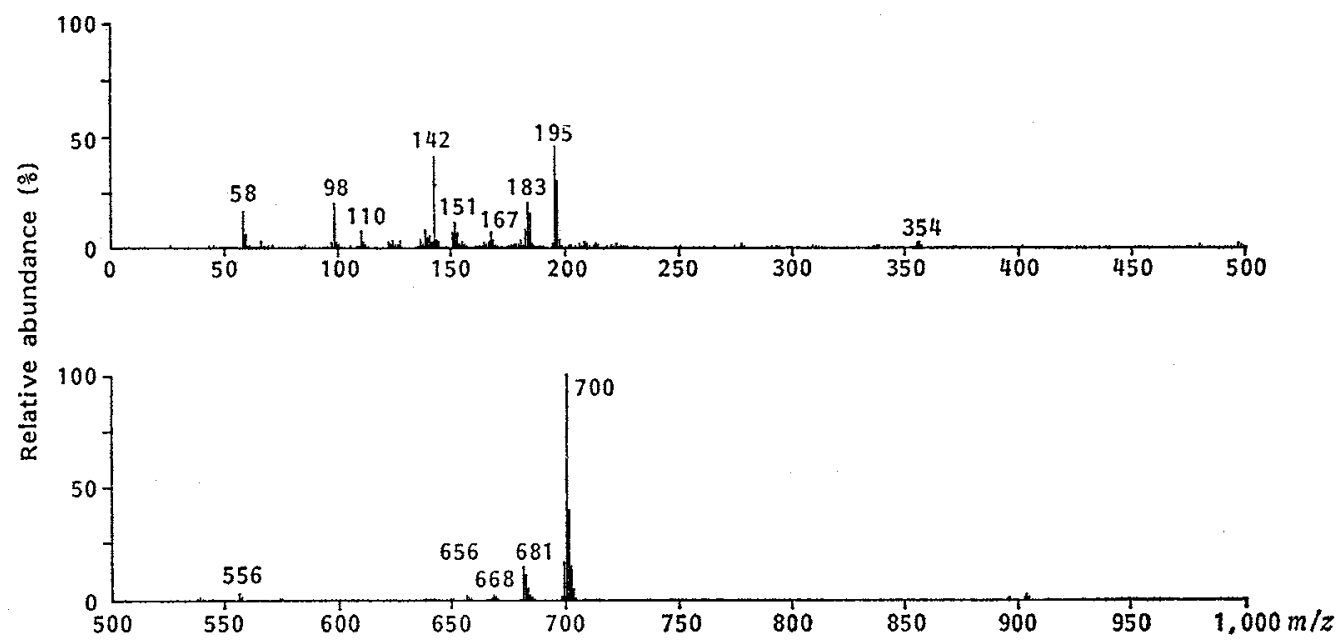

(B)

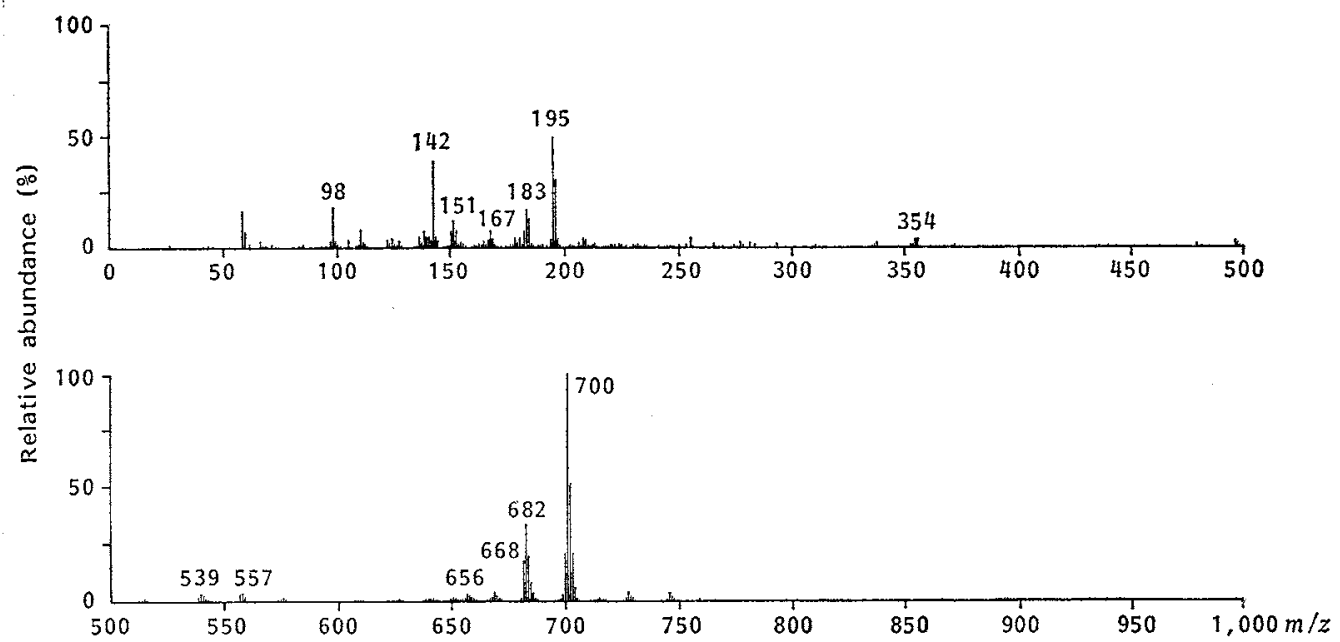

A as the TLC system mentioned earlier and therefore to separate easily from paulomycin.

The production of the paulomycin complex by S. paulus strain 273 (UC 5142, NRRL 12251) and the isolation and separation of paulomycins $A, A_{2}, B, C, D, E$, and $F$ gave us the opportunity to reexamine the relationship of paulomycins to senfolomycins. As reported in previous papers, ${ }^{1,2)}$ all paulomycins have negative rotation in methanol but positive in chloroform. An authentic sample of senfolomycin A run under identical conditions gave negative values in both solvents, as reported by the Lederle workers. Therefore, senfolomycin A can be differentiated from all paulomycins on the basis of the optical rotation behavior.

FAB-MS differentiated all known paulomycins, execpt paulomycin $\mathrm{E}$, from senfolomycin $\mathrm{A}$. Fig. 1 presents the FAB-MS spectra of paulomycin $\mathrm{E}^{2}$ (upper part) and senfolomycin $\mathrm{A}$ (lower part). Simple inspection shows that the two spectra are practically identical. The molecular compositions of 
Fig. 2. HPLC comparison of paulomycin $E$ and senfolomycin $A$.
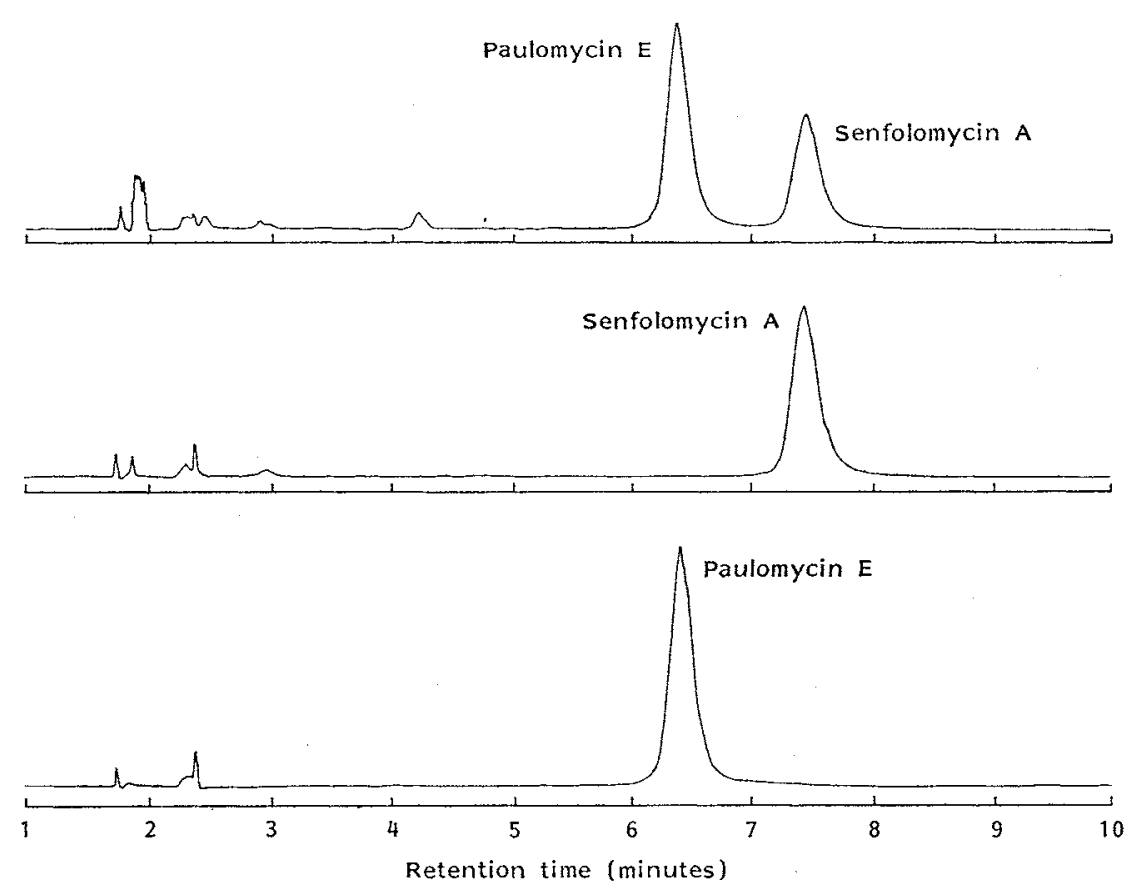

both antibiotics was found by HR-MS to be the same $\mathrm{C}_{29} \mathrm{H}_{38} \mathrm{~N}_{2} \mathrm{O}_{18} \mathrm{~S}$. The HPLC and TLC comparisons of paulomycin $\mathrm{E}$ and senfolomycin A are presented in Figs. 2 and 3. The two antibiotics easily separated on a Zorbax stainless steel column packed with $\mathrm{C}-8$ reverse phase silica. The chromatogram was run isocratically using water - THF - acetonitrile $(3: 1: 1)$ containing $0.25 \mathrm{M}$ acetic acid, as the mobile phase. Paulomycin E had a retention time of $c a .6 .5$ minutes. The antitibiotics were also separated on cellulose TLC plates using $\mathrm{pH} 7.0,0.1 \mathrm{M}$ phosphate buffer. The bioactive materials were observed by bioautography on $M$. luteus-seeded agar trays. Paulomycin E, like in the HPLC comparison described earlier, is more polar than senfolomycin A.

All paulomycins and senfolomycin A gave
Fig. 3. TLC separation of paulomycin E and senfolomycin $\mathrm{A}$.

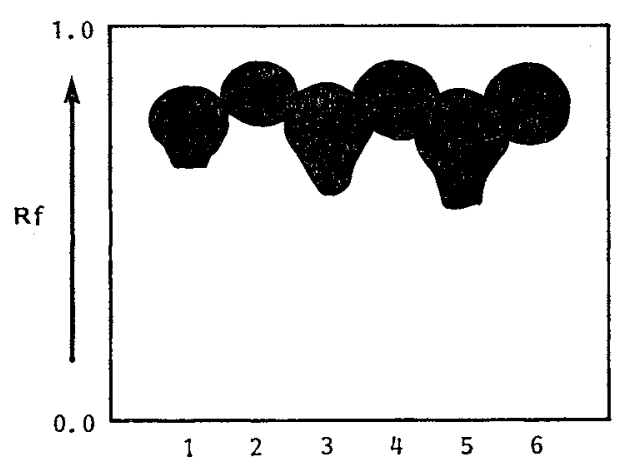

1,3,5: Senfolomycin $\mathrm{A}$ at 5,10 , and $20 \mu \mathrm{g}$ respectively.

2,4,6: Paulomycin E at 5, 10, and $20 \mu \mathrm{g}$ respectively.

Cellulose, pH 7.0, $0.1 \mathrm{~m}$ phosphate buffer; bioautography on Micrococcus luteus-seeded agar trays.

negative ion FAB-MS which are almost identical at the low mass (below $m / z 360$ ) area of the spectra. Fig. 4 presents major ions common to all paulomycins and senfolomycin $\mathrm{A}$ and their structural assignment. These ions, obtained by fragmentation of paulomycins A and B were mass measured to ions of the matrix (tetraethylene glycol). All ions are derived from the aglycone part of paulomycins. 
Fig. 4. Ion fragments observed in the negative ion HRFAB-MS of paulomycins and senfolomycin A.

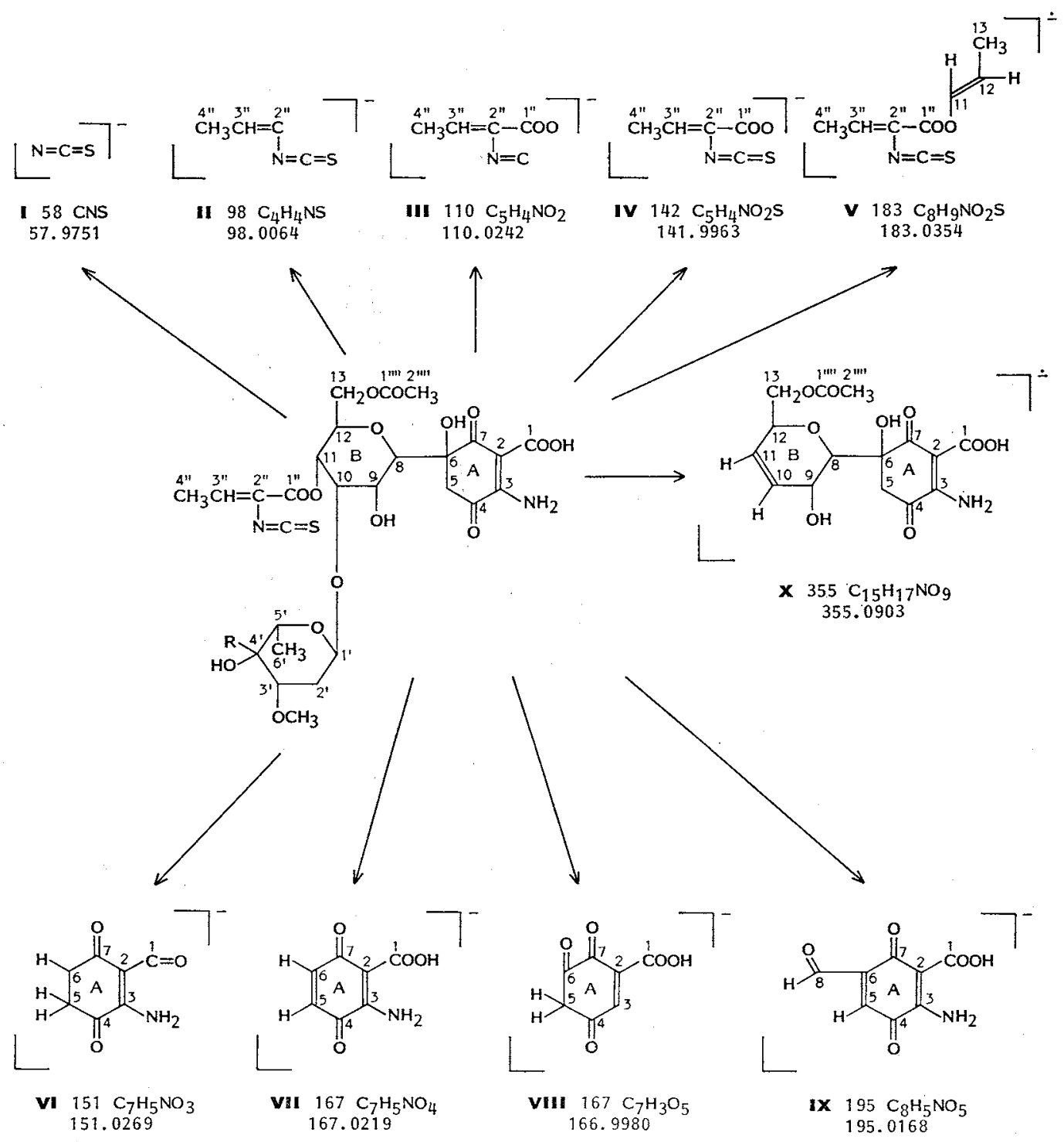

The ions in the upper part of Fig. 4 originate from the paulic acid area which contains the isothiocyanate group. The ions in the lower part of the Fig. 4 result from ring A-ring B fragmentation.

The mass spectral results indicate that both paulomycin $\mathrm{E}$ and senfolomycin A contain the same moiety 1 which is responsible for the characteristic UV and IR spectra of these compounds. This conclusion agrees with the ${ }^{1} \mathrm{H}$ NMR data tabulated in Table 2. Furthermore, the ${ }^{1} \mathrm{H}$ NMR studies establish that the stereochemistry at C-8, C-9, C-10, C-11, and C-12 is identical in both antibiotics.

The ${ }^{13} \mathrm{C}$ spectrum of senfolomycin $\mathrm{A}$ obtained at $50 \mathrm{MHz}$ is shown in Fig. 5. The multiplicity of the peaks shown in Table 3 was determined by a DEPT experiment. The peak at approx $\delta 143$ is due to the carbon of the isothiocyanate group. The small height of this peak is caused by a long relaxation time for this carbon and can be increased by using a two second delay between pulses. A total 
Table 2. ${ }^{1} \mathrm{H}$ NMR data on the aglycone (1) part of paulomycin $\mathrm{E}^{a}$ and senfolomycin A.

\begin{tabular}{|c|c|c|c|c|c|c|}
\hline \multirow{2}{*}{$\begin{array}{l}\text { Assign- } \\
\text { ment }^{\mathrm{c}}\end{array}$} & \multicolumn{3}{|c|}{ Paulomycin $\mathrm{E}$} & \multicolumn{3}{|c|}{ Senfolomycin A } \\
\hline & $\begin{array}{l}\text { Chemical } \\
\text { shift }(\delta)\end{array}$ & Multiplicityd & $J(\mathrm{~Hz})$ & $\begin{array}{l}\text { Chemical } \\
\text { shift }(\delta)\end{array}$ & Multiplicity ${ }^{a}$ & $J(\mathrm{~Hz})$ \\
\hline 8-H & 3.70 & d & $J_{9}=10.10$ & 3.67 & $\mathrm{~d}$ & $J_{g}=10.30$ \\
\hline $9-\mathrm{H}$ & 3.51 & ddd & $\begin{array}{l}J_{\mathrm{OH}}=8.20 \\
J_{8}=10.10 \\
J_{10}=2.47\end{array}$ & 3.56 & dd & $\begin{array}{l}J_{8}=10.30 \\
J_{10}=2.93\end{array}$ \\
\hline $10-\mathrm{H}$ & 4.31 & $\mathrm{t}$ & $\begin{array}{l}J_{9}=2.47 \\
J_{11}=2.47\end{array}$ & 4.45 & $t$ & $\begin{array}{l}J_{0}=2.93, \\
J_{11}=2.93\end{array}$ \\
\hline $11-\mathrm{H}$ & 4.69 & dd & $\begin{array}{l}J_{10}=2.47, \\
J_{12}=10.24\end{array}$ & 4.75 & $\mathrm{dd}$ & $\begin{array}{l}J_{10}=2.93 \\
J_{12}=10.09\end{array}$ \\
\hline $12-\mathrm{H}$ & 4.16 & ddd & $\begin{array}{l}J_{11}=10.24, \\
J_{13 \mathrm{~A}}=4.43, \\
J_{13 \mathrm{~B}}=2.44\end{array}$ & 4.14 & $\mathrm{dt}$ & $\begin{array}{l}J_{11}=10.09 \\
J_{13}=3.42\end{array}$ \\
\hline
\end{tabular}

a The ${ }^{1} \mathrm{H}$ NMR spectrum of paulomycin $\mathrm{E}$ was obtained in $\mathrm{CDCl}_{3}$ on a Bruker WM-500 operating at $500 \mathrm{MHz}$.

b The ${ }^{1} \mathrm{H}$ NMR spectrum of senfolomycin $\mathrm{A}$ was obtained in $\mathrm{CDCl}_{3}$ on a Varian XL-200 spectrometer operating at $200 \mathrm{MHz}$.

e For proton assignment see 1.

a Multiplicity: $d=$ doublet, $t=$ triplet, $d d=$ doublet of doublets, $d d d=$ doublet of doublets of doublets, $\mathrm{dt}=$ doublet of triplet.

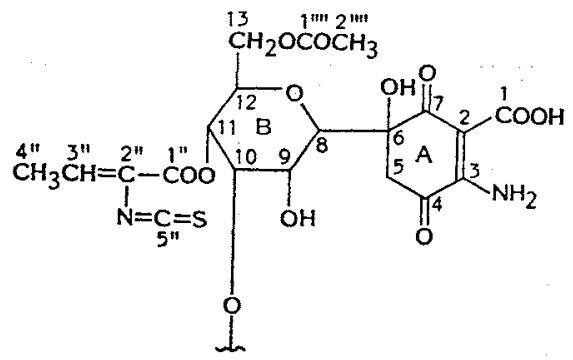

1

of 29 carbons were counted in agreement with FAB-MS data.

Table 3 presents the ${ }^{13} \mathrm{C}$ chemical shifts of senfolomycin $\mathrm{A}$ and paulomycin $\mathrm{E}$. Carbons $1 \sim 13$ have been assigned to part of the aglycone (1) of these antibiotics which as mentioned earlier is identical. Carbons $1^{\prime \prime}$ to $5^{\prime \prime}$ are the five carbons of the isothiocyanate-containing unsaturated acid which we call paulic acid. Carbons $1^{\prime \prime \prime \prime}$ and $2^{\prime \prime \prime \prime}$ are the two carbons of the acetate group attached to the C-13 of 1. Carbons $1^{\prime}$ to $8^{\prime}$ are the eight carbons present in the sugars of senfolomycin A and paulomycin E. All carbon shifts in the two molecules, except for those associated with the sugars differ by less than $\delta$ 1.3. The downfield shift of $\mathrm{C}^{-1} \mathbf{1}^{\prime}$ and $\mathrm{C}-5^{\prime}$ in senfolomycin A suggests a change in stereochemistry in $\mathrm{C}-3^{\prime}$.

Since the structural differences between paulomycin $\mathrm{E}$ and senfolomycin $\mathrm{A}$ reside in the sugar moieties of the respective antibiotics we will discuss in detail the ${ }^{1} \mathrm{H}$ NMR studies which yielded the structure of these sugars. Fig. 6 lists the chemical shifts observed in the ${ }^{13} \mathrm{C}$ and ${ }^{1} \mathrm{H}$ NMR spectra of both paulomycin $\mathrm{E}$ and senfolomycin $\mathrm{A}$. Let us consider first the data on paulomycin $\mathrm{E}$. $1^{\prime}-\mathrm{H}$ has two small couplings to the two protons at $\mathrm{C}-2^{\prime}$ and is therefore equatorial. $3^{\prime}-\mathrm{H}$ is a doublet of dou- 
Fig. 5. ${ }^{13} \mathrm{C}$ NMR spectrum of senfolomycin A.

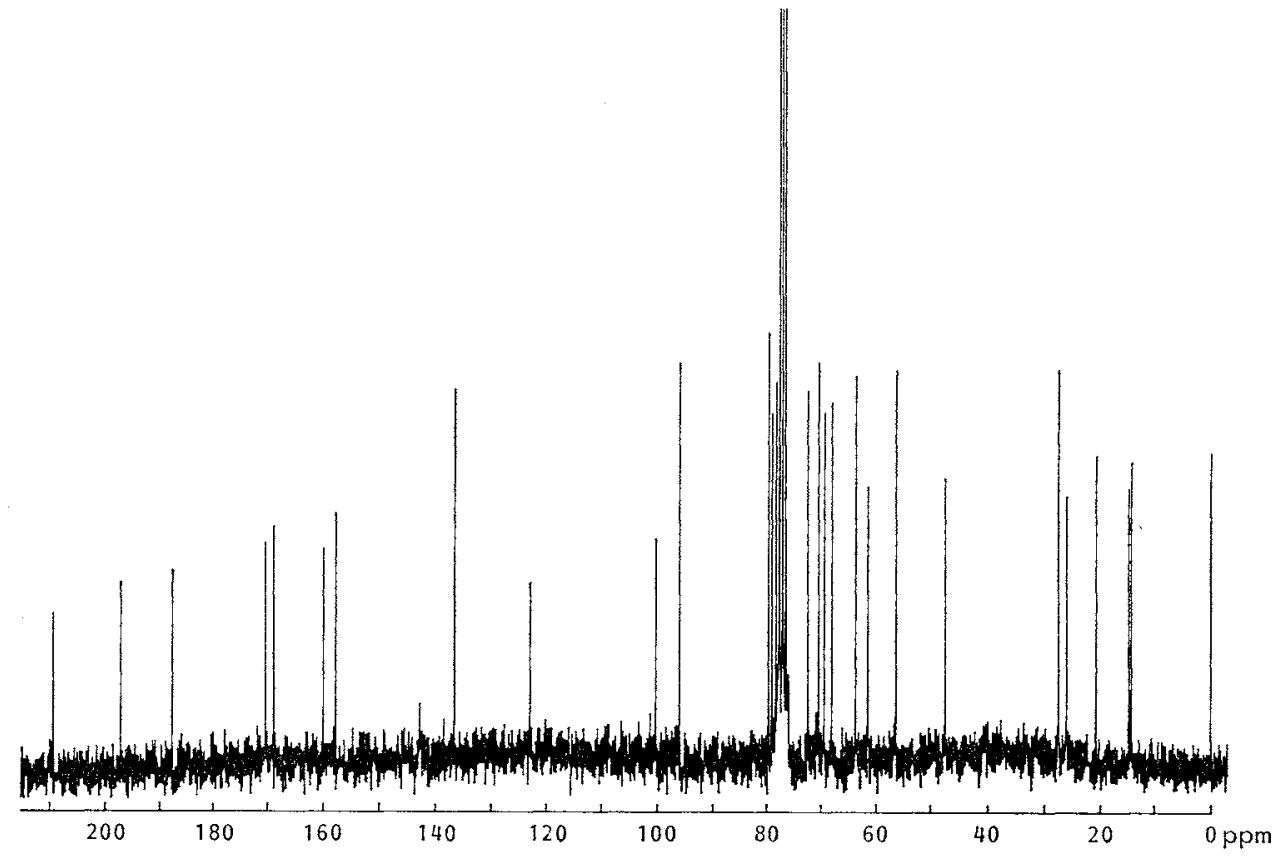

Table 3. Chemical shifts observed in the ${ }^{13} \mathrm{C}$ NMR spectra of senfolomycin $\mathrm{A}$ and paulomycin $\mathrm{E}$.

\begin{tabular}{|c|c|c|c|c|}
\hline Carbon No. ${ }^{\mathrm{a}}$ & Senfolomycin A & Paulomycin E & Multiplicity & $\Delta$ \\
\hline 1 & 169.15 & 169.10 & $\mathrm{~s}$ & -0.05 \\
\hline 2 & 157.97 & 158.06 & $\mathbf{s}$ & +0.09 \\
\hline 3 & 100.11 & 99.58 & s & -0.53 \\
\hline 4 & 197.37 & 197.33 & s & -0.04 \\
\hline 5 & 47.66 & 47.57 & $\mathbf{t}$ & -0.09 \\
\hline 6 & 77.80 & 77.71 & $\mathbf{s}$ & -0.09 \\
\hline 7 & 187.65 & 187.64 & s & -0.01 \\
\hline 8 & 79.51 & 78.30 & d & -1.21 \\
\hline 9 & 68.30 & 68.80 & d & +0.50 \\
\hline 10 & 78.80 & 77.90 & d & -0.90 \\
\hline 11 & 69.57 & 69.72 & $\mathrm{~d}$ & +0.15 \\
\hline 12 & 72.54 & 72.09 & d & -0.45 \\
\hline 13 & 61.71 & 61.70 & $\mathbf{t}$ & -0.01 \\
\hline $1^{\prime}$ & 95.98 & 99.81 & d & +3.83 \\
\hline $2^{\prime}$ & 26.08 & 29.83 & $\mathbf{t}$ & +3.75 \\
\hline $3^{\prime}$ & 70.72 & 75.44 & $\mathrm{~d}$ & +4.72 \\
\hline $3^{\prime} \alpha$ & 56.65 & 56.77 & $q$ & +0.12 \\
\hline $4^{\prime}$ & 77.99 & 81.23 & s & +3.24 \\
\hline $5^{\prime}$ & 63.84 & 68.96 & d & +5.12 \\
\hline $6^{\prime}$ & 14.80 & 14.63 & $\mathrm{q}$ & -0.17 \\
\hline $7^{\prime}$ & 209.50 & 211.76 & $\mathrm{~s}$ & +2.26 \\
\hline $8^{\prime}$ & 27.62 & 27.25 & $q$ & -0.37 \\
\hline $1^{\prime \prime}$ & 160.21 & 160.20 & s & -0.01 \\
\hline $2^{\prime \prime}$ & 122.89 & 122.80 & s & -0.09 \\
\hline $3^{\prime \prime}$ & 136.65 & 136.57 & $\mathrm{~d}$ & -0.08 \\
\hline $4^{\prime \prime}$ & 14.23 & 13.92 & $q$ & -0.31 \\
\hline $5^{\prime \prime}$ & 142.80 & 143.27 & s & +0.47 \\
\hline $1^{\prime \prime \prime \prime}$ & 170.69 & 170.83 & s & +0.14 \\
\hline $2^{\prime \prime \prime \prime \prime}$ & 20.74 & 20.61 & $q$ & -0.13 \\
\hline
\end{tabular}

a For numbering of carbons see Fig. 8. 
Fig. 6. ${ }^{13} \mathrm{C}$ and ${ }^{1} \mathrm{H}$ NMR data on the sugar moieties of paulomycin $\mathrm{E}$ and senfolomycin $\mathrm{A}$.

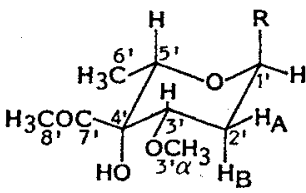

Paulomycin E

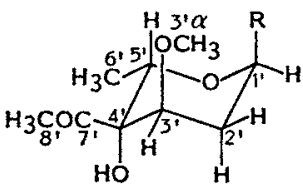

Senfolomycin A

\begin{tabular}{|c|c|c|c|c|}
\hline \multirow{2}{*}{$\begin{array}{l}\text { Assign- } \\
\text { ment }\end{array}$} & \multicolumn{2}{|r|}{ Paulomycin E } & \multicolumn{2}{|c|}{ Senfolomycin $\mathrm{A}$} \\
\hline & ${ }^{13} \mathrm{C}(\delta)$ & ${ }^{1} \mathrm{H}(\delta, J$ in $\mathrm{Hz})$ & ${ }^{13} \mathrm{C}(\delta)$ & ${ }^{1} \mathrm{H}(\delta, J$ in $\mathrm{Hz})$ \\
\hline $1^{\prime}$ & 99.81 & $5.00, J_{2^{\prime} B}=3.59, J_{2^{\prime} \mathrm{A}}<1$ & 95.98 & $5.30, J_{2^{\prime}}=2.31$ \\
\hline $\begin{array}{l}2^{\prime} \mathrm{A} \\
2^{\prime} \mathrm{B}\end{array}$ & 29.83 & $\begin{array}{l}2.23, J_{2^{\prime} \mathrm{B}}=13.22, J_{1^{\prime}}<1, J_{3^{\prime}}=5.05 \\
1.96, J_{2^{\prime} \mathrm{A}}=13.22, J_{1^{\prime}}=3.59, \\
J_{3^{\prime}}=11.70\end{array}$ & 26.08 & $\begin{array}{l}2.18, J_{1^{\prime}}=2.31, \\
J_{3^{\prime}}=2.86\end{array}$ \\
\hline $3^{\prime}$ & 75.44 & $4.07, J_{2^{\prime} \mathrm{A}}=5.05, J_{2^{\prime} \mathrm{B}}=11.70$ & 70.72 & $3.34, J_{2^{\prime}}=2.86$ \\
\hline $3^{\prime} \alpha$ & 56.77 & 3.56 & 56.65 & 3.44 \\
\hline $4^{\prime}$ & 81.23 & - & 77.99 & - \\
\hline $5^{\prime}$ & 68.96 & $5.30, J_{6^{\prime}}=6.38$ & 63.84 & $4.58, J_{8^{\prime}}=6.38$ \\
\hline $6^{\prime}$ & 14.63 & $1.08, J_{5^{\prime}}=6.38$ & 14.80 & $1.00, J_{5^{\prime}}=6.38$ \\
\hline $7^{\prime}$ & 211.76 & - & 209.50 & - \\
\hline $8^{\prime}$ & 27.25 & 2.33 & 27.62 & 2.32 \\
\hline
\end{tabular}

Fig. 7. Nuclear Overhauser experiments on senfolomycin A.

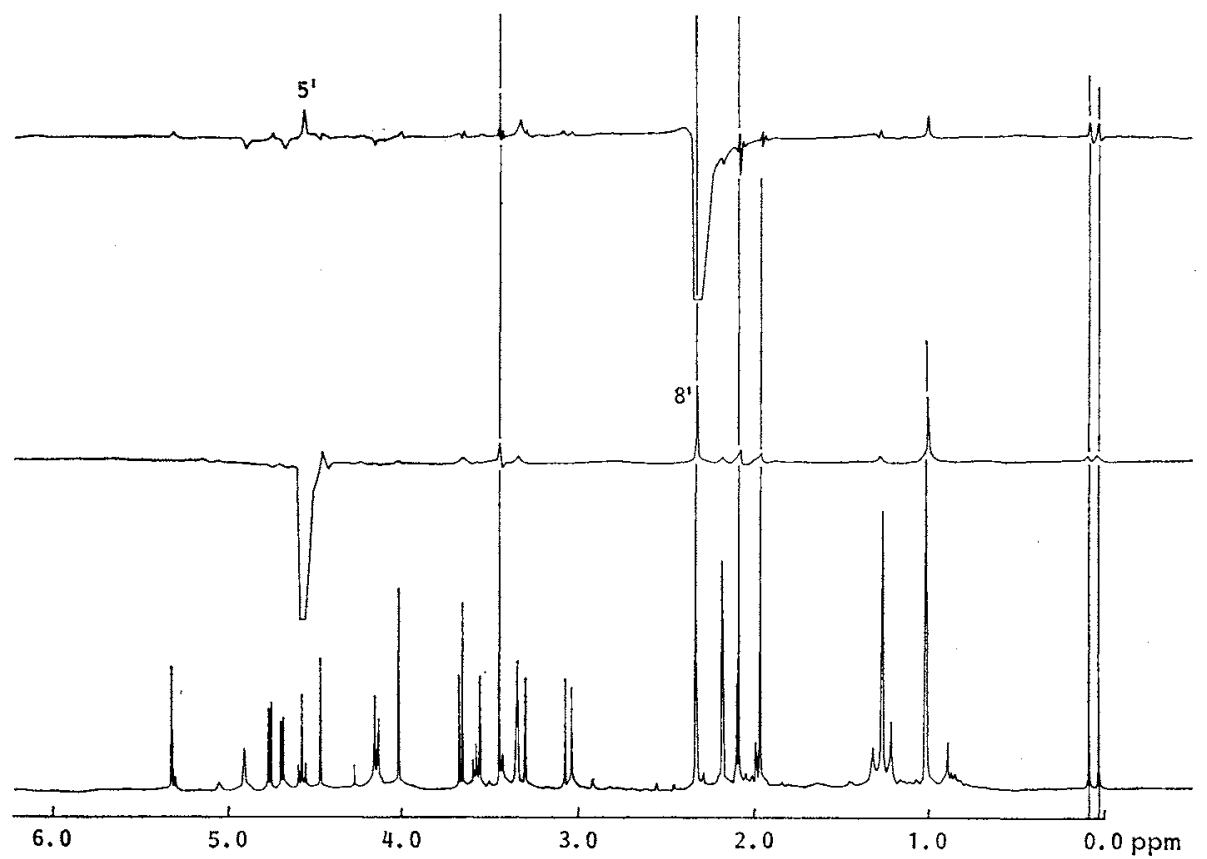

blets with a large diaxial coupling of $11.70 \mathrm{~Hz}$ to one of the proton at $\mathrm{C}-2^{\prime}$ and therefore it is axial. This requires that the $\mathrm{OCH}_{3}$ attached to $\mathrm{C}-3^{\prime}$ of paulomycin $\mathrm{E}$, like that of paulomycins $\mathrm{A}$ and $\left.\mathrm{B},{ }^{6}\right)$ is below the plane of the sugar. In senfolomycin $A$ the $1^{\prime}-\mathrm{H}$ couplings are less than $3 \mathrm{~Hz}$ indicating that the $1^{\prime}$ hydrogen is still equatorial. The $3^{\prime}$ hydrogen in this molecule is now a triplet with a $J$ of 2.86 
Fig. 8. Structures of paulomycins A, E, and F and senfolomycins A and B.

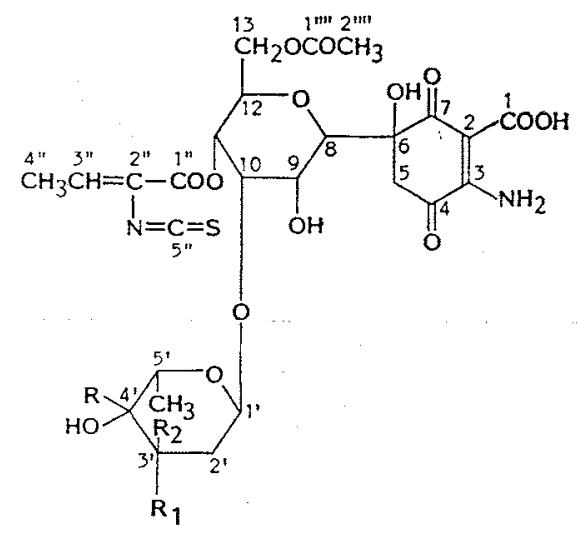

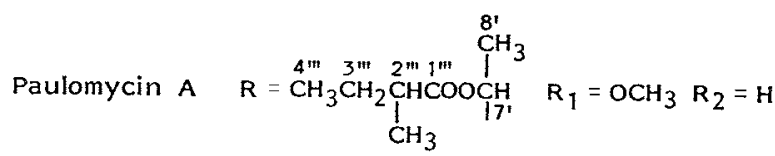

Paulomycin $E \quad R=O=\overbrace{1}^{\stackrel{8}{C} H^{\prime}} \quad R_{1}=O_{3} R_{2}=H$

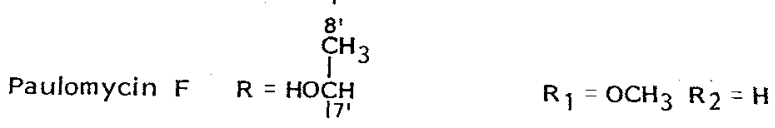

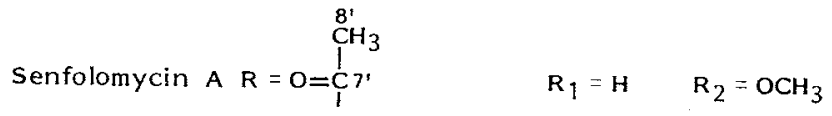

Senfolomycin B R $=\underset{\substack{\mathrm{H} H \\ \stackrel{\mathrm{C}}{\mathrm{C}} \mathrm{H}_{3}}}{\stackrel{8}{\prime}} \mathrm{R}_{1}=\mathrm{H} \quad \mathrm{R}_{2}=\mathrm{OCH}_{3}$

$\mathrm{Hz}$ which means that the $3^{\prime}$ hydrogen is equatorial and therefore the $\mathrm{OCH}_{3}$ group attached to $\mathrm{C}-3^{\prime}$ is axial and above the plane of the sugar. The ${ }^{1} \mathrm{H}$ shifts for $6^{\prime}-\mathrm{H}$ of $\delta 1.08$ and 1.00 and the ${ }^{13} \mathrm{C}$ shifts for C-6' of 14.63 and 14.80 for paulomycin $E$ and senfolomycin A respectively indicate the same stereochemistry for the $\mathrm{C}\left(6^{\prime}\right) \mathrm{H}_{3}$. These results agree with the $\mathrm{C}-13$ data which also suggested a difference in stereochemistry at $\mathrm{C}-3^{\prime}$ of the sugars of senfolomycin $\mathrm{A}$ and paulomycin $\mathrm{E}$.

The remaining question in regard to the structure of the senfolomycin sugar is the relative stereochemistry of the acetyl and hydroxy groups attached at C-4'. A nuclear Overhauser effect (NOE), which is a measure of how close in space two groups are, can be seen at the acetyl methyl (attached at C-4') when $5^{\prime}-\mathrm{H}$ is irradiated (Fig. 7). Likewise, an NOE can be seen at $5^{\prime}-\mathrm{H}$ when the acetyl methyl at $\mathrm{C}-4^{\prime}$ is irradiated. This confirms that the acetyl group is equatorial and the $\mathrm{OH}$ is axial at $\mathrm{C}-4^{\prime}$. Therefore, the only difference between the structures of paulomycin $E$ and senfolomycin $A$ is the stereochemistry of the methoxy group attached at C-3' in the sugar moieties of these antibiotics (Fig. 8). Regarding senfolomycin $B$ we know that it is more polar than senfolomycin $A$ and that, like senfolomycin A, shows strong negative rotation in methanol. Analytical data do not help in determining molecular composition but the UV and IR spectra of both senfolomycins are identical. These spectral data suggest that senfolomycin B also contains $\mathbf{1}$, that is the aglycone moiety present in paulo- 
Fig. 9. ${ }^{1} \mathrm{H}$ NMR spectra ${ }^{\mathrm{a}}$ of senfolomycins $\mathrm{A}(\mathrm{A})$ and $\mathrm{B}(\mathrm{B})$.

(A)

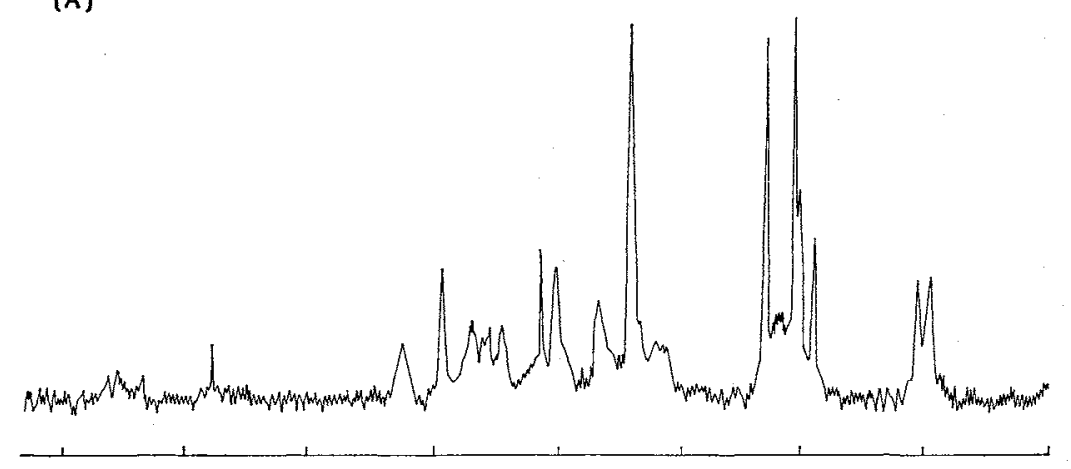

(B)

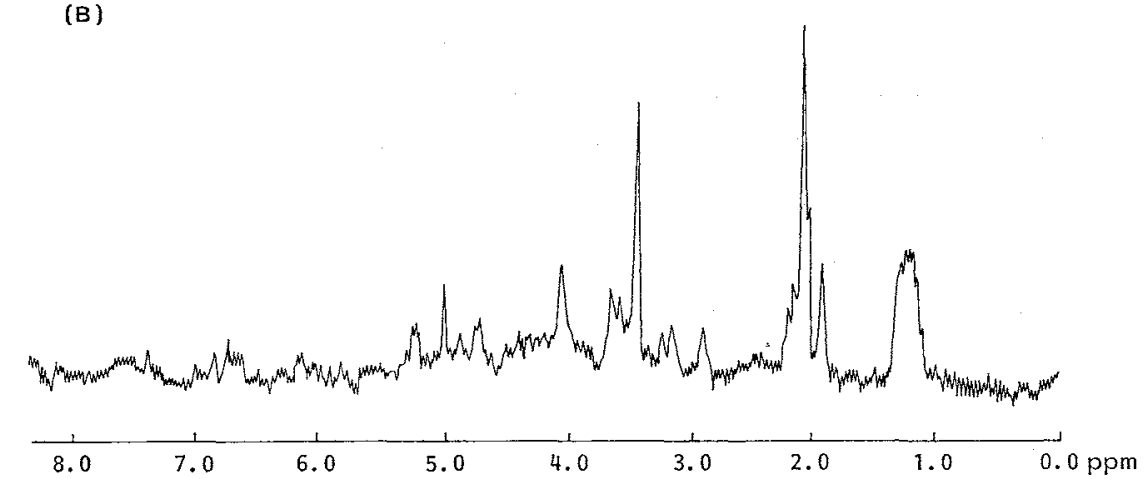

a As reported by DeVOE et al..$^{5}$.

mycins and senfolomycin A. This would mean that the difference in structures between senfolomycins $A$ and $B$ resides in the sugars.

Fig. 9 presents the ${ }^{1} \mathrm{H}$ NMR spectra of senfolomycins $\mathrm{A}$ and $\mathrm{B}$ as reported by DEVOE and his co-workers in a U.S. Patent.5) The main

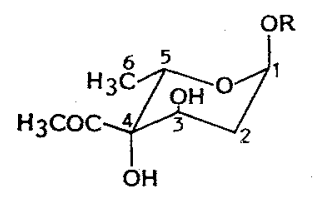

$2 \mathrm{R}=$ Aglycone

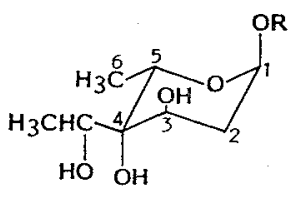

$3 \mathbf{R}=$ Aglycone features in the proton spectrum of senfolomycin $\mathrm{A}$ are signals due to 3 protons at $\delta 3.35$ assigned to the methoxy group present in the sugar. A singlet of $3 \mathrm{H}$ at $\delta 2.35$ is due to the acetyl group at $\mathrm{C}-4^{\prime}$ of the sugar, a singlet of $3 \mathrm{H}$ at $\delta 2.1$ is due to the 13-O-acetate present in both senfolomycins and paulomycins, a doublet of $3 \mathrm{H}$ at $\delta 1.9 \sim 2.05$ is due to the methyl group of the paulic acid and finally a doublet at $\delta 1.05$ is due to the three proton of the C-3' methyl group of the sugar of senfolomycin A.

The ${ }^{1} \mathrm{H}$ NMR spectrum of senfolomycin $\mathrm{B}$ is quite similar to that of senfolomycin $\mathrm{A}$ with the exception that the absorption at $\delta 2.35$ due to the acetyl group at $\mathrm{C}-4^{\prime}$ of the sugar is missing. Instead, an unresolved broad absorption at $\delta 1.2 \sim 1.4 \mathrm{ppm}$ due to six protons is present. This can be explained if we assume that the acetyl group at $\mathrm{C}-4^{\prime}$ of senfolomycin $\mathrm{A}$ has been reduced and that the broad absorption at $\delta 1.2 \sim 1.4$ is due to the $6^{\prime}$ - and $8^{\prime}$-methyls of the senfolomycin B sugar. Therefore, senfolomycin $\mathrm{B}$ is dihydro-senfolomycin $\mathrm{A}$ and the relationship between senfolomycins $\mathrm{A}$ and $\mathrm{B}$ parallels that between paulomycins $\mathrm{E}$ and $\mathrm{F}$ respectively (Fig. 8). 
Table 4. Antibacterial spectra ${ }^{a, b}$ of paulomycins A and E and senfolomycin A.

\begin{tabular}{lccc}
\hline \multicolumn{1}{c}{ Organism } & \multicolumn{3}{c}{ MIC $(\mu \mathrm{g} / \mathrm{ml})$} \\
\cline { 2 - 4 } & Paulomycin A & Paulomycin E & Senfolomycin A \\
\hline Staphylococcus aureus UC 9218 & 0.06 & 0.25 & 0.125 \\
S. aureus UC 3665 & 0.125 & 1 & 0.5 \\
S. aureus UC 6685 & 0.125 & 0.5 & 0.25 \\
S. aureus UC 9213 & 0.125 & 0.5 & 0.25 \\
S. epidermidis UC 30031 & 0.06 & 0.5 & 0.125 \\
S. faecalis UC 694 & 0.5 & 4 & 4 \\
S. pneumoniae UC 41 & 0.06 & 0.06 & 0.125 \\
\hline a Test method: Agar dilution, pH 6.0. & & & \\
b In vitro antibacterial data were provided by Mr. G. E. ZurENko and BETTY H. YAGI of The Upjohn \\
Company.
\end{tabular}

Sugar component $\mathbf{2}$ is present in quinocycline B and isoquinocycline B while sugar 3 is part of the quinocycline $\mathrm{A}$, isoquinocycline A molecules. ${ }^{7)} \quad$ Therefore, the 3-O-methylated forms of sugars 2 and 3 are present in senfolomycin $\mathrm{A}$ and senfolomycin $\mathrm{B}$, respectively.

Biological Properties of Paulomycins A, E, and Senfolomycin A

The in vitro antibacterial spectrum of paulomycins $\mathrm{A}, \mathrm{E}$ and senfolomycin $\mathrm{A}$ against selected organisms is presented in Table 4. Senfolomycin A, like the paulomycins, is mainly active against Gram-positive organisms especially Staphylococcus aureus including strains resistant to penicillin, streptomycin, neomycin, macrolide and lincosaminide antibiotics. Senfolomycin A is more active than paulomycin $\mathrm{E}$ and less active than paulomycin $\mathrm{A}$ against the test organisms recorded in Table 4.

Acknowledgment

The authors express their appreciation to Mr. K. J. GEIPEL for technical assistance, to Mr. G. E. ZURENKo and Mrs. B. H. YAGI for biological testing.

\section{References}

1) Argoudelis, A. D.; T. A. Brinkley, T. F. Brodasky, J. A. Buege, H. F. Meyer \& S. A. Mizsak: Paulomycins $A$ and B. Isolation and characterization. J. Antibiotics 35: 285 294, 1982

2) Argoudelis, A. D.; L. Baczynskyj, W. J. HaAk, W. M. Knoll, S. A. MizsaK \& F. B. Shilliday: New paulomycins produced by Streptomyces paulus. J. Antibiotics $41: 157 \sim 169,1988$

3) Mitscher, L. A.; W. McCrae, S. E. DeVoe, A. J. Shay, W. K. Hausmann \& N. Bohonos: Senfolomycin $A$ and B, new antibiotics. Antimicrob. Agents Chemother.-1965: 828 831, 1966

4) Wiley, P. F.: A new antibiotic, U-43,120. J. Antibiotics 29: 587 589, 1976

5) DeVoe, S. E. \& L. A. Mitscher (Lederle): Antibiotic $6950 \beta$ and method of production using Streptomyces ochrosporus. U.S. 3,377,243, Apr. 9, 1968, assigned to Cyanamid Co., U.S.A.

6) Wiley, P. F.; S. A. Mizsak, L. Baczynskyj, A. D. Argoudelis, D. J. Duchamp \& W. Watt: The structure and chemistry of paulomycin. J. Org. Chem. 51:2493 2499, 1986

7) Matern, U.; H. Grijebach, W. Karl \& A. Achenbach: Structure of the sugar components of the quinocycline complex. Eur. J. Biochem. 29: 1 4, 1972 